Subscriber access provided by NEW YORK UNIV

Article

\title{
Magnetic Interactions and Energy Barrier Enhancement in Core/Shell Bimagnetic Nanoparticles
}

Gabriel Carlos Lavorato, Davide Peddis, Enio Lima, Jr., Horacio E. Troiani, Elisabetta Agostinelli, Dino Fiorani, Roberto Daniel Zysler, and Elin Lilian Winkler

J. Phys. Chem. C, Just Accepted Manuscript • DOI: 10.1021/acs.jpcc.5b04448 • Publication Date (Web): 11 Jun 2015

Downloaded from http://pubs.acs.org on June 16, 2015

\section{Just Accepted}

"Just Accepted" manuscripts have been peer-reviewed and accepted for publication. They are posted online prior to technical editing, formatting for publication and author proofing. The American Chemical Society provides "Just Accepted" as a free service to the research community to expedite the dissemination of scientific material as soon as possible after acceptance. "Just Accepted" manuscripts appear in full in PDF format accompanied by an HTML abstract. "Just Accepted" manuscripts have been fully peer reviewed, but should not be considered the official version of record. They are accessible to all readers and citable by the Digital Object Identifier (DOI®). "Just Accepted" is an optional service offered to authors. Therefore, the "Just Accepted" Web site may not include all articles that will be published in the journal. After a manuscript is technically edited and formatted, it will be removed from the "Just Accepted" Web site and published as an ASAP article. Note that technical editing may introduce minor changes to the manuscript text and/or graphics which could affect content, and all legal disclaimers and ethical guidelines that apply to the journal pertain. ACS cannot be held responsible for errors or consequences arising from the use of information contained in these "Just Accepted" manuscripts. 
Dark-field TEM micrographs of $\mathrm{CoO} / \mathrm{CoFe}_{2} \mathrm{O}_{4}$ (upper panel) and $\mathrm{ZnO} / \mathrm{CoFe}_{2} \mathrm{O}_{4}$ (bottom panel) and a schematic representation of the core/shell structures. Inset: size distributions of $\mathrm{CoO} / \mathrm{CoFe}_{2} \mathrm{O}_{4}$ and $\mathrm{ZnO} / \mathrm{CoFe}_{2} \mathrm{O}_{4}$ nanoparticles. $126 \times 62 \mathrm{~mm}(300 \times 300 \mathrm{DPI})$ 
Temperature dependence of magnetization for (a) $\mathrm{ZnO} / \mathrm{CoFe}_{2} \mathrm{O}_{4}$ nanoparticles (b) $\mathrm{CoO} / \mathrm{CoFe}_{2} \mathrm{O}_{4}$ nanoparticles (full symbols indicate ZFC curves and empty symbols indicate FC curves, for clarity the curves were scaled by a fixed factor). (c) Mean blocking temperature as a function of the applied field (dashed lines are a guide to the eye). $84 \times 167 \mathrm{~mm}(300 \times 300 \mathrm{DPI})$ 


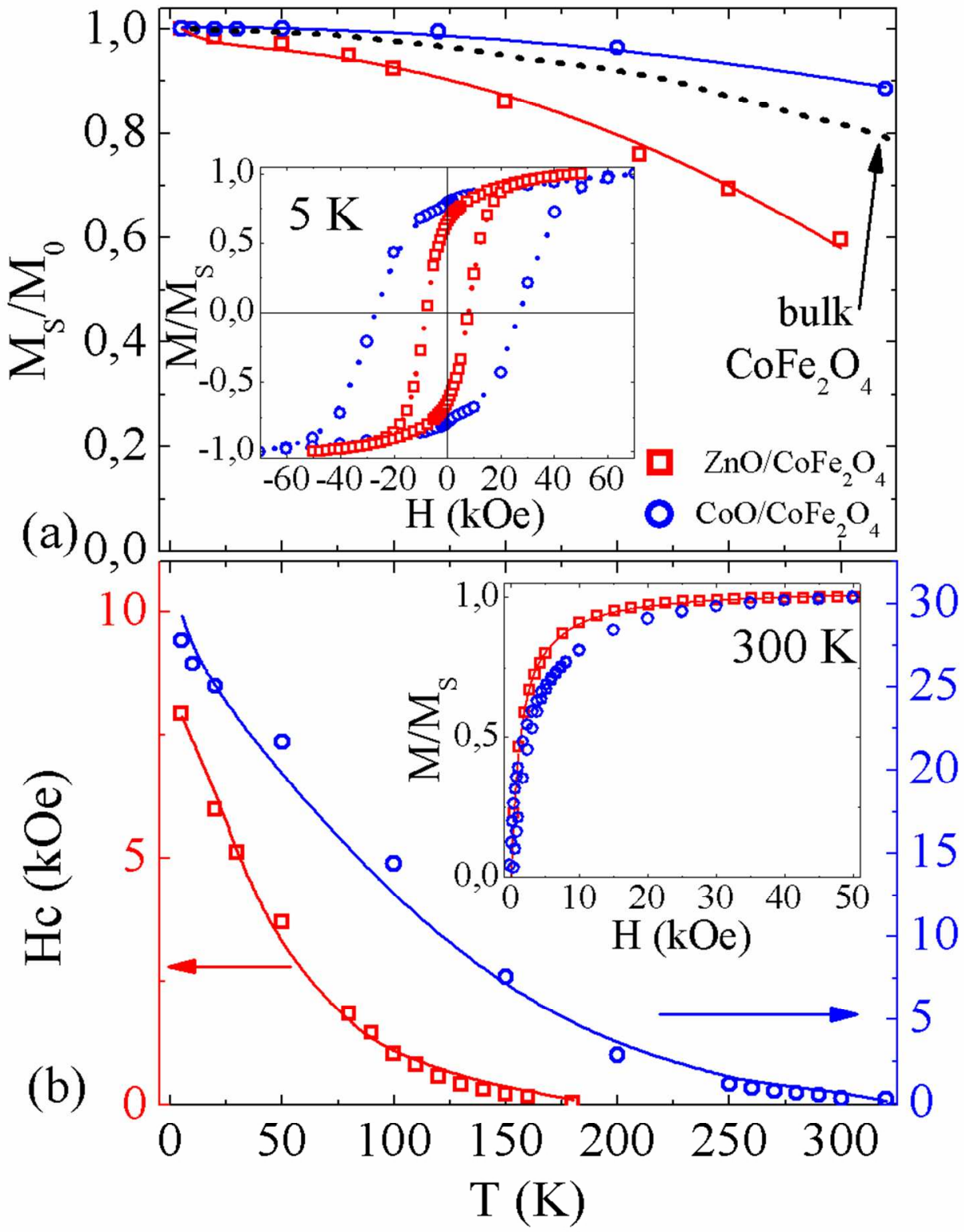

(a) Temperature dependence of the saturation magnetization ratio $\mathrm{M}_{\mathrm{s}} / \mathrm{M}_{0}$ for $\mathrm{ZnO} / \mathrm{CoFe}_{2} \mathrm{O}_{4}$ and $\mathrm{CoO} / \mathrm{CoFe}_{2} \mathrm{O}_{4}$ nanoparticles (bulk $\mathrm{CoFe}_{2} \mathrm{O}_{4}$ experimental values from ref 41 are shown for comparison). Inset: Hysteresis loops at $5 \mathrm{~K}$. (b) Temperature dependence of the coercive field. Inset: field dependence of magnetization at $300 \mathrm{~K}$. (full lines represent the corresponding fits). $84 \times 107 \mathrm{~mm}(300 \times 300 \mathrm{DPI})$ 
DCD (empty symbols) and IRM (full symbols) curves for (a) $\mathrm{ZnO} / \mathrm{CoFe}_{2} \mathrm{O}_{4}$ nanoparticles and (b) $\mathrm{CoO} / \mathrm{CoFe}_{2} \mathrm{O}_{4}$ nanoparticles measured at $10 \mathrm{~K}$. (c) $\delta \mathrm{m}$ plots and (insets) irreversible susceptibilities calculated from the DCD and IRM curves (lines are a guide to the eye).

$172 \times 353 \mathrm{~mm}(300 \times 300 \mathrm{DPI})$ 


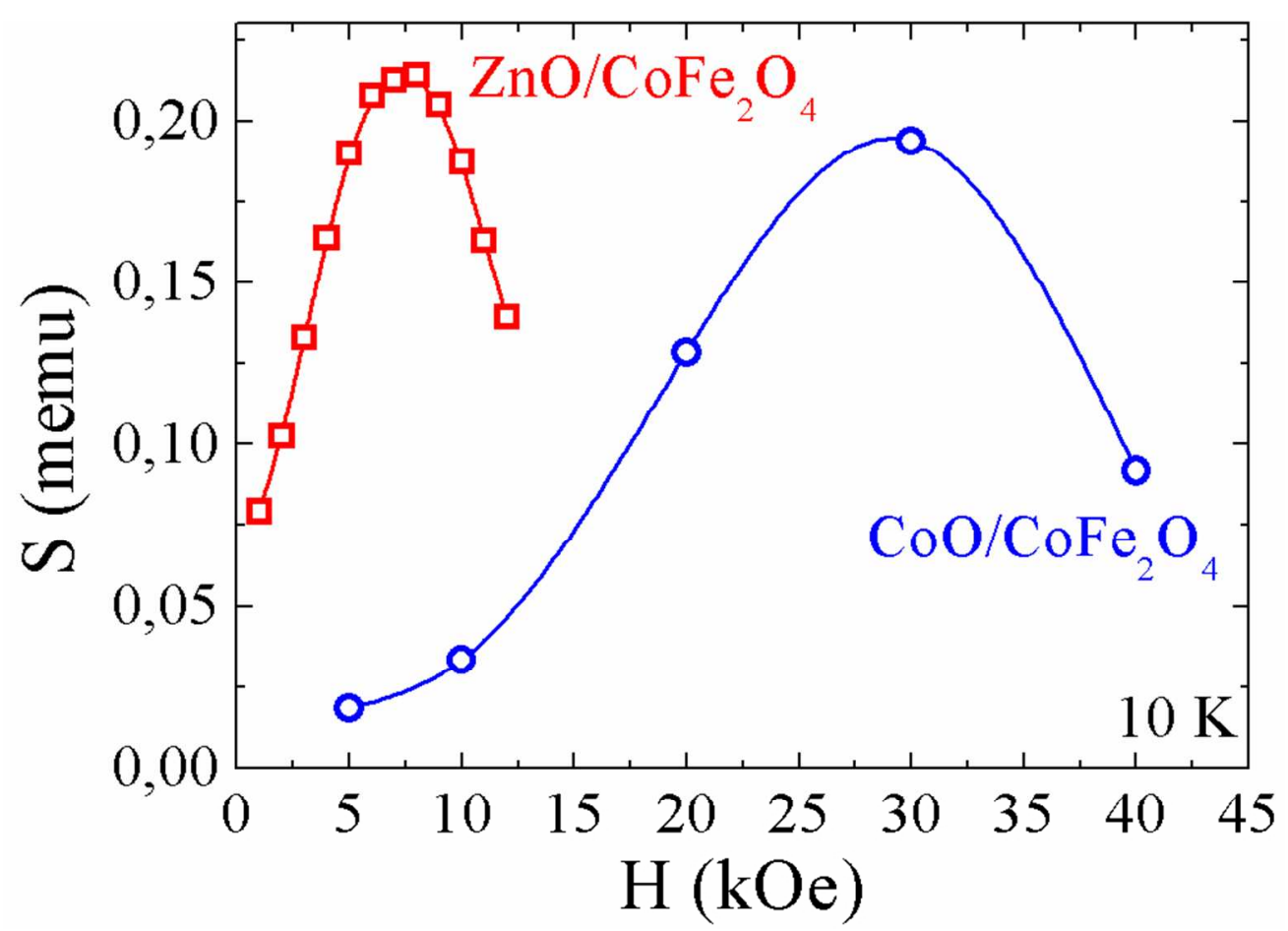

Magnetic viscosity coefficient (S) as a function of the reverse field for $\mathrm{ZnO} / \mathrm{CoFe}_{2} \mathrm{O}_{4}$ and $\mathrm{CoO} / \mathrm{CoFe}_{2} \mathrm{O}_{4}$ nanoparticles (lines are a guide to the eye). $84 \times 59 \mathrm{~mm}(300 \times 300 \mathrm{DPI})$ 


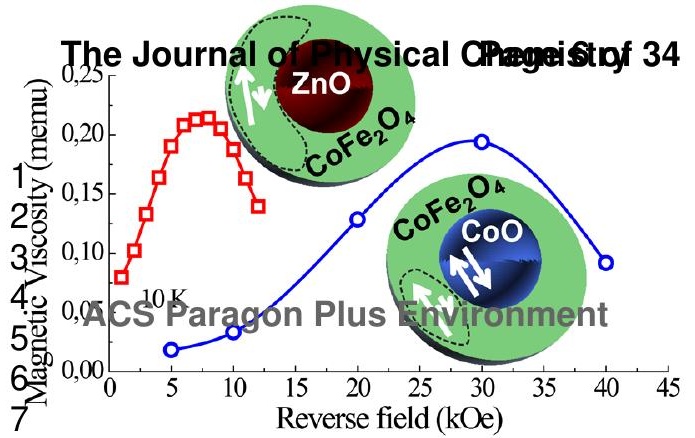




\title{
Magnetic Interactions and Energy Barrier
}

\section{Enhancement in Core/Shell Bimagnetic}

\section{Nanoparticles}

Gabriel C. Lavorato ${ }^{\dagger, \xi}$, Davide Peddis ${ }^{\dot{t}, \xi}$, Enio Lima Jr ${ }^{\dagger, \xi}$, Horacio E. Troiani ${ }^{\dagger}$, Elisabetta Agostinelli $^{t, \xi}$, Dino Fiorani ${ }^{\dagger, \xi}$, Roberto D. Zysler ${ }^{\dagger, \xi}$, Elin L. Winkler ${ }^{\dagger, \xi, *}$

$†$ Centro Atómico Bariloche and CONICET, 8400 S.C. de Bariloche, RN, Argentina.

\$ Istituto di Struttura della materia-CNR, Area della Ricerca di Roma, Po.Box 10, I-00015 Monterotondo (Roma), Italy.

$\S$ Argentine-Italian Joint Laboratory of Nanomagnetism, LIANAM, Laboratorio

Resonancias Magnéticas-CNEA, Argentina/ Istituto di Struttura della Materia, CNR, Italy.

\begin{abstract}
In this work we studied the dynamic and static magnetic properties of $\mathrm{ZnO}$-core $/ \mathrm{CoFe}_{2} \mathrm{O}_{4-}$ shell and $\mathrm{CoO}$-core/ $\mathrm{CoFe}_{2} \mathrm{O}_{4}$-shell nanoparticles. Both systems are formed by a core of $\sim 4$ $\mathrm{nm}$ of diameter encapsulated in a shell of $\sim 2 \mathrm{~nm}$ of thickness. The mean blocking temperature changes from $106(7) \mathrm{K}$ to $276(5) \mathrm{K}$ when the core is diamagnetic or antiferromagnetic, respectively. Magnetic remanence studies revealed the presence of
\end{abstract}


weak dipolar inter-particle interactions, where $\mathrm{H}_{\text {int }}$ is approximately $-0.1 \mathrm{kOe}$ for $\mathrm{ZnO} / \mathrm{CoFe}_{2} \mathrm{O}_{4}$ and $-0.9 \mathrm{kOe}$ for $\mathrm{CoO} / \mathrm{CoFe}_{2} \mathrm{O}_{4}$, playing a minor role in the magnetic behavior of the materials. Relaxation experiments provided evidence that the magnetization reversal process of $\mathrm{CoFe}_{2} \mathrm{O}_{4}$ is strongly dependent on the magnetic order of the core. At 10 $\mathrm{K}$, activation volumes of $\sim 46(6)$ and $\sim 69(5) \mathrm{nm}^{3}$ were found for $\mathrm{CoO} / \mathrm{CoFe} \mathrm{O}_{4}$ and $\mathrm{ZnO} / \mathrm{CoFe}_{2} \mathrm{O}_{4}$ nanoparticles, respectively, corresponding to one-third and one-fifth of the total shell volume. While the magnetic behavior of $\mathrm{ZnO} / \mathrm{CoFe} \mathrm{O}_{4}$ nanoparticles is strongly affected by the surface disorder, the exchange coupling at the $\mathrm{CoO} / \mathrm{CoFe}_{2} \mathrm{O}_{4}$ interface rules the magnetization reversal and the nanoparticles' thermal stability by inducing a larger energy barrier and promoting smaller switching volume.

KEYWORDS: Magnetic Nanoparticles, Exchange-coupling, Magnetic anisotropy, Interparticle interactions, Intraparticle interactions, Cobalt ferrite.

\section{INTRODUCTION}

The search for new magnetic materials has motivated the fabrication and study of nanostructures with tuned and improved properties that would allow the development of novel and promising technologies. Among nanostructured materials, magnetic nanoparticles (NPs) attract great interest because they can be applied in different fields as data storage, ${ }^{1-4}$ permanent magnets, ${ }^{5-8}$ optics, ${ }^{9}$ catalysis ${ }^{10}$ and nanomedicine. ${ }^{11,12}$ In particular, the possibility of fabricating bimagnetic NPs, that combine materials with different magnetic order and anisotropy, has added a new degree of freedom to better tune specific properties. ${ }^{13-17}$ The progress in the production of advanced magnetic NPs is based on the synergy between new fabrication techniques and the understanding of the origin of the interactions governing the magnetic behavior. A number of bimagnetic 
antiferromagnetic (AFM)/ferrimagnetic (FiM) interface exchange-coupled core/shell systems have shown improved properties such as an increase of the coercive field $\left(\mathrm{H}_{\mathrm{C}}\right)$ and thermal stability ${ }^{18}$ and high and tunable exchange bias fields $\left(\mathrm{H}_{\mathrm{EB}}\right) .{ }^{19,20}$ However, the complexity of these nanostructures adds new factors, e.g. inter and intra-particle interactions, shape, surface and/or magnetocrystalline anisotropy, size distribution, that make more difficult the analysis. The mentioned factors directly affect the energy barrier distribution and, as a consequence, they alter the magnetization reversal process and determine the range of application of a particular magnetic material.

In this work we studied the influence of the interface exchange interaction on the magnetization reversal process by comparing two bimagnetic nanoparticle systems with analogous size and morphology. One system is formed by NPs with a diamagnetic $\mathrm{ZnO}$ core encapsulated in a FiM $\mathrm{CoFe}_{2} \mathrm{O}_{4}$ shell while the other one consists of NPs with an AFM $\mathrm{CoO}$ core encapsulated in a $\mathrm{FiM} \mathrm{CoFe}_{2} \mathrm{O}_{4}$ shell. The energy barrier distribution of $\mathrm{ZnO} / \mathrm{CoFe}_{2} \mathrm{O}_{4}$ system is expected to be determined by size, shape and distribution of magnetic anisotropy, but may also be modified by the inter-particle interactions. For the $\mathrm{CoO} / \mathrm{CoFe}_{2} \mathrm{O}_{4}$ system, besides the previously mentioned contributions to the energy barrier distribution, intra-particle interactions due to the exchange interaction at the AFM/FiM interface could play a relevant role in the NPs' magnetic moment reversal. The samples were studied through various conventional DC magnetization measurements with the aim of determining the energy barrier distributions and how they are affected by inter- and intra-particle interactions. In addition, the magnetic viscosity, originated by the thermally activated transition over the energy barrier, and the activation volume, defined when the system overcomes the energy maximum, were analyzed taking into account their correlation with surface effects and magnetic interactions. 


\section{SAMPLE PREPARATION AND EXPERIMENTAL SETUP}

$\mathrm{ZnO}$ core/ $\mathrm{CoFe}_{2} \mathrm{O}_{4}$ shell and $\mathrm{CoO}$ core/ $\mathrm{CoFe}_{2} \mathrm{O}_{4}$ shell nanoparticles were synthesized by combining the chemical route of high temperature decomposition of organometallic precursors with a seed-mediated process. ${ }^{21,22}$ A detailed description of the synthesis is reported in ref 23. To fabricate $\mathrm{ZnO} \mathrm{NPs}, 3 \mathrm{mmol} \mathrm{Zn}(\mathrm{II})$ acetylacetonate $\left(\mathrm{Zn}(\mathrm{acac})_{2}\right)$ were mixed with long-chain alcohol 1-2 octanediol (1.8 mmol), diphenyl ether (190 mmol), oleic acid $(9 \mathrm{mmol})$ and oleylamine $(9 \mathrm{mmol})$ and heated up to $\mathrm{T} \sim 260{ }^{\circ} \mathrm{C}$ for $120 \mathrm{~min}$. The $\mathrm{CoFe}_{2} \mathrm{O}_{4}$ was overgrown by adding $\mathrm{Co}(\mathrm{acac})_{2}$ and $\mathrm{Fe}(\mathrm{acac})_{3}$ with $1: 2$ molar ratio $(0.6: 1.2$ mmol) together with 1-2 octanediol (2 $\left.10^{-2} \mathrm{mmol}\right)$, diphenyl ether (95 mmol), oleic acid (3 mmol) and oleylamine ( $3 \mathrm{mmol})$. The solution was magnetically stirred and heated up to the boiling temperature $\mathrm{T} \sim 260^{\circ} \mathrm{C}$ for $120 \mathrm{~min}$. After cooling down to room temperature, the NPs were washed several times with a mix of ethanol and toluene 10:1 solution. In order to improve the sample crystallinity, ${ }^{24}$ the obtained dry powder was annealed at $\mathrm{T} \sim$ $300{ }^{\circ} \mathrm{C}$ in air atmosphere for $2 \mathrm{~h}$. Afterwards, the sample was re-dispersed in ethanol and the suspension was dropped on a copper grid for transmission electron microscopy (TEM) observation. The morphology and particle size were evaluated in a Philips CM200 UT TEM microscope operating at $200 \mathrm{kV}$ by measuring around 300 particles of each sample in either bright-field and dark-field micrographs. The DC magnetization measurements were performed by a Quantum Design SQUID magnetometer, equipped with a superconducting coil that produces magnetic fields in the range $\pm 50 \mathrm{kOe}$. Samples in the form of powders were immobilized in an epoxy resin to prevent any movement of the NPs during the measurements. Magnetization versus temperature measurements were performed using 
zero-field-cooled (ZFC) and field-cooled (FC) protocols. ZFC and FC magnetization measurements were carried out by cooling the sample from room temperature to $5 \mathrm{~K}$ in zero magnetic field, then, a static magnetic field was applied. $\mathrm{M}_{\mathrm{ZFC}}$ was measured during the warm-up from $5 \mathrm{~K}$ to $300 \mathrm{~K}$, whereas $\mathrm{M}_{\mathrm{FC}}$ was recorded during the subsequent coolingdown. The field dependence of remanent magnetization was measured using the isothermal remanent magnetization (IRM) and direct current demagnetization (DCD) protocols. The initial state for an IRM measurement is a totally demagnetized sample cooled in zero magnetic field. In the present case, an external field was applied and kept for $10 \mathrm{~s}$; then, it was switched off and the remanence was measured $\left(M_{\text {IRM }}\right)$. The process was repeated increasing the field up to saturation. In a DCD measurement, the initial state is the magnetically saturated one. An external field of $50 \mathrm{kOe}$ was applied and kept for $10 \mathrm{~s}$; then, a small external field in the direction opposite to magnetization was applied and, after $10 \mathrm{~s}$, it was switched off and the remanent magnetization $\left(\mathrm{M}_{\mathrm{DCD}}\right)$ was measured. This was repeated while increasing the field up to $+50 \mathrm{kOe}$. The time dependence of magnetization was investigated by saturating the samples with a $50 \mathrm{kOe}$ applied field and then measuring the magnetization after the application of reverse fields with different magnitude and values close to the coercivity of each sample.

\section{EXPERIMENTAL RESULTS AND DISCUSSION}

\subsection{Structural Characterization}

TEM images evidence that the samples are composed by $\mathrm{ZnO}$ NPs (or CoO NPs) encapsulated in $\mathrm{CoFe}_{2} \mathrm{O}_{4}$. The samples consist of $\sim 8 \mathrm{~nm}$ NPs formed by $\sim 4 \mathrm{~nm}$ diameter $\mathrm{ZnO}$ (or $\mathrm{CoO}$ ) cores surrounded by a $\sim 2 \mathrm{~nm}$ thick cobalt ferrite shell (as detailed in Table 1). The inset of Figure 1 shows the NPs' size dispersion, obtained from TEM 
measurements, where a log-normal distribution is observed for both systems. Characteristic dark-field TEM micrographs, obtained by the intensity of a fraction of $\mathrm{CoFe}_{2} \mathrm{O}_{4}(111)$ diffraction ring, evidence the core/shell morphology of the material (Figure 1); for clarity, a schematic representation of the NPs' architecture is also reported. A comprehensive structural characterization is reported elsewhere. ${ }^{23}$
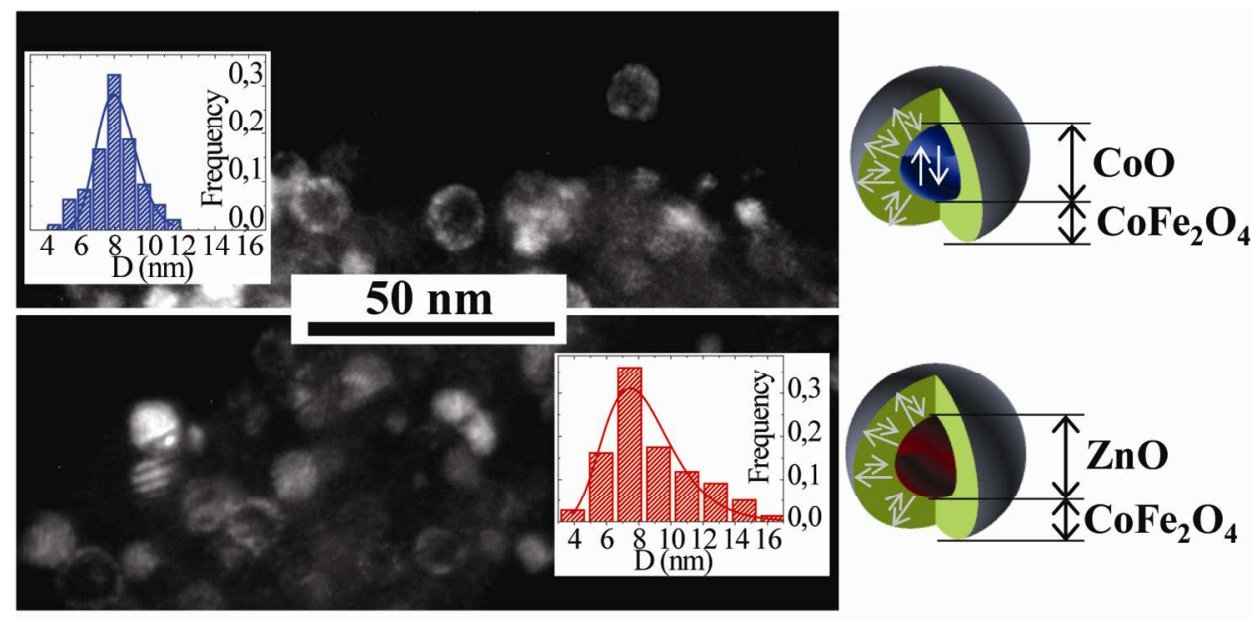

Figure 1 Dark-field TEM micrographs of $\mathrm{CoO} / \mathrm{CoFe}_{2} \mathrm{O}_{4}$ (upper panel) and $\mathrm{ZnO} / \mathrm{CoFe}_{2} \mathrm{O}_{4}$ (bottom panel) and a schematic representation of the core/shell structures. Inset: size distributions of $\mathrm{CoO} / \mathrm{CoFe}_{2} \mathrm{O}_{4}$ and $\mathrm{ZnO} / \mathrm{CoFe}_{2} \mathrm{O}_{4}$ nanoparticles.

\subsection{Magnetic Behavior}

Magnetization versus temperature curves were measured following $\mathrm{ZFC}$ and $\mathrm{FC}$ protocols at applied fields in the range $0.05-20 \mathrm{kOe}$ (see Figure 2 and Figure $\mathrm{S} 1$ at the supporting information). The ZFC and FC magnetization measurements suggest the presence of a blocking process typical of an assembly of magnetic NPs with a distribution of blocking temperatures $\left(T_{B}\right)$. The maximum of the low-field ZFC curve is located at $200 \mathrm{~K}$ for $\mathrm{ZnO} / \mathrm{CoFe}_{2} \mathrm{O}_{4} \mathrm{NPs}$ and above room temperature for the $\mathrm{CoO} / \mathrm{CoFe}_{2} \mathrm{O}_{4}$ system when the measurement is performed at $0.1 \mathrm{kOe}$ and $0.05 \mathrm{kOe}$ respectively, and both shift 
toward lower temperatures when the measurement is performed applying higher magnetic fields. In addition, the FC curves of both samples show a weak temperature dependence below the ZFC maximum, suggesting the presence of magnetic interactions.

In order to quantify the dependence of $T_{B}$ on the magnetic field we refer to the Néel model for an assembly of identical non-interacting single domain NPs. Within this model $T_{B}$ can be defined as the temperature where the relaxation time $(\tau)$ is equal to the experimental "time window" $\left(\tau_{m}\right): T_{B}=\frac{\Delta E}{\ln \left({ }^{\tau_{m} / \tau}\right) k_{B}}$, where $\Delta E$ corresponds to the energy barrier and $\mathrm{k}_{\mathrm{B}}$ is the Boltzmann constant. However, real particle systems present interactions and a distribution of size and magnetic anisotropy that simultaneously affect the energy barrier. The irreversibility between $\mathrm{ZFC}$ and $\mathrm{FC}$ curves arises from the distribution of energy barriers or blocking temperatures $f\left(T_{B}\right)$, therefore the mentioned $T_{B}$ distribution could be determined through the relation $f\left(T_{B}\right) \sim(1 / T) d\left(M_{Z F C}-M_{F C}\right) / d T{ }^{25-}$ ${ }^{27}$ and the mean blocking temperature, $\left\langle T_{B}\right\rangle$, can be defined as follows:

$$
\left\langle T_{B}\right\rangle=\frac{\int_{0}^{\infty} T_{B} f\left(T_{B}\right) d T_{B}}{\int_{0}^{\infty} f\left(T_{B}\right) d T_{B}} \quad \text { (Equation 1) }
$$

The insets of Figures 2a-b show $f\left(T_{B}\right)$ calculated from the low-field ZFC and FC magnetization curves. It is important to notice that the size distributions obtained from TEM measurements show typical log-normal size distributions with a single peak for both systems (see insets of Figure 1). However, while the $f\left(T_{B}\right)$ curve for $\mathrm{ZnO} / \mathrm{CoFe}_{2} \mathrm{O}_{4}$ particles also shows a lognormal temperature dependence with a single maximum, the bimagnetic $\mathrm{CoO} / \mathrm{CoFe}_{2} \mathrm{O}_{4}$ system presents two relative maxima located at $\sim 230 \mathrm{~K}$ and $\sim 290$ $\mathrm{K}$. These results evidence that the $\mathrm{CoO} / \mathrm{CoFe}_{2} \mathrm{O}_{4}$ system presents other contributions to the energy barrier, in addition to the size dispersion. In particular, the high temperature 
anomaly is still observed at higher applied fields (as shown in Figure S2 at the supporting information) and its position matches well with the Néel temperature of CoO $\left(\mathrm{T}_{\mathrm{N}} \sim 290 \mathrm{~K}\right)$. The mean blocking temperature, $\left\langle T_{B}\right\rangle$, calculated at low fields from Equation 1, changes from $\left\langle T_{B}\right\rangle=106(7) K$ to $\left\langle T_{B}\right\rangle=276(5) K$ when the core is diamagnetic or AFM, respectively. Such significant difference implies an enhancement of the thermal stability of $\mathrm{CoO} / \mathrm{CoFe}_{2} \mathrm{O}_{4}$ system ascribed to the presence of interface exchange interaction.

The magnetic field dependence of the magnetization reversal process is usually analyzed through the relation $\left\langle T_{B}\right\rangle(H)=T_{0}\left[1-\left(H / H_{0}\right)^{2 / 3}\right]$ obtained for single domain NPs, where $H_{0}$ and $T_{0}$ are the coercive field at zero temperature and the blocking temperature at zero field, respectively. ${ }^{25,28-30}$ Figure $2 \mathrm{c}$ presents $\left\langle T_{B}\right\rangle$ as a function of $H^{2 / 3}$ : while $\mathrm{ZnO} / \mathrm{CoFe}_{2} \mathrm{O}_{4}$ NPs present a linear trend, as expected for non-interacting particles, ${ }^{25,31}$ for $\mathrm{CoO} / \mathrm{CoFe}_{2} \mathrm{O}_{4}$ NPs the variation does not follow the $H^{2 / 3}$ dependence. Such discrepancy suggests that for $\mathrm{CoO} / \mathrm{CoFe}_{2} \mathrm{O}_{4} \mathrm{NPs}$ both magnetic intra-particle and/or inter-particle interactions are playing a major role in determining the energy barrier. 
Figure 2 Temperature dependence of magnetization for (a) $\mathrm{ZnO} / \mathrm{CoFe}_{2} \mathrm{O}_{4}$ nanoparticles (b) $\mathrm{CoO} / \mathrm{CoFe}_{2} \mathrm{O}_{4}$ nanoparticles (full symbols indicate $\mathrm{ZFC}$ curves and empty symbols indicate FC curves, for clarity the curves were scaled by a fixed factor). (c) Mean blocking temperature as a function of the applied field (dashed lines are a guide to the eye). 
Table 1 Summary of the characterization parameters: mean diameter $\langle D\rangle$ and diameter dispersion $\left(\sigma_{D}\right)$ from TEM measurements, coercive field at $5 \mathrm{~K}\left(H_{C} 5 \mathrm{~K}\right)$, mean blocking temperature $\left\langle T_{B}\right\rangle$, inter-particle interaction field estimated from remanence studies at $10 \mathrm{~K}$ $\left(H_{\text {int }} 10 \mathrm{~K}\right)$ and activation volume calculated from relaxation and remanence measurements at $10 \mathrm{~K}\left(V_{A C T} 10 \mathrm{~K}\right)$.

\begin{tabular}{|l|l|l|l|l|l|l|}
\hline Sample & $\begin{array}{l}\langle D\rangle \\
(\mathrm{nm})\end{array}$ & $\begin{array}{l}\sigma_{D} \\
(\mathrm{~nm})\end{array}$ & $\begin{array}{l}H_{C} 5 \mathrm{~K} \\
(\mathrm{kOe})\end{array}$ & $\begin{array}{l}\left\langle T_{B}\right\rangle \\
(\mathrm{K})\end{array}$ & $\begin{array}{l}H_{\text {int }} 10 \mathrm{~K} \\
(\mathrm{kOe})\end{array}$ & $\begin{array}{l}V_{A C T} 10 \mathrm{~K} \\
\left(\mathrm{~nm}^{3}\right)\end{array}$ \\
\hline $\mathrm{ZnO} / \mathrm{CoFe}_{2} \mathrm{O}_{4}$ & 8.1 & 1.6 & $7.8(1)$ & $106(7)$ & $-0.1(2)$ & $69(5)$ \\
\hline $\mathrm{CoO} / \mathrm{CoFe}_{2} \mathrm{O}_{4}$ & 8.2 & 1.2 & $27.8(2)$ & $276(5)$ & $-0.9(3)$ & $46(6)$ \\
\hline
\end{tabular}

The field dependence of magnetization was measured at different temperatures for both samples. The insets of Figures 3a-b show the $\mathrm{M}(\mathrm{H})$ curves measured at $5 \mathrm{~K}$ and $300 \mathrm{~K}$, respectively. The low temperature $(5 \mathrm{~K})$ hysteresis curve shows a remarkable increase of the coercive field when the core is AFM: $\mathrm{H}_{\mathrm{C}}$ changes from $7.8(1) \mathrm{kOe}$ to $27.8(2) \mathrm{kOe}$ for $\mathrm{ZnO} / \mathrm{CoFe}_{2} \mathrm{O}_{4}$ and $\mathrm{CoO} / \mathrm{CoFe}_{2} \mathrm{O}_{4}$, respectively. Besides, at room temperature the magnetization of $\mathrm{ZnO} / \mathrm{CoFe}_{2} \mathrm{O}_{4} \mathrm{NPs}$ is fully reversible reflecting the superparamagnetic behavior of the sample. In this case, the magnetic volume at $300 \mathrm{~K}$ can be derived by fitting the experimental data with a Langevin function and a lognormal distribution for the magnetic moments. ${ }^{32}$ A mean magnetic moment per particle of $2328(70) \mu_{\mathrm{B}}$ was estimated, which corresponds to an average magnetic volume of $46(3) \mathrm{nm}^{3}$ calculated from the $\mathrm{CoFe}_{2} \mathrm{O}_{4}$ bulk magnetic moment per unit formula and its lattice parameter. ${ }^{33}$ Considering that the overall shell volume is $235 \mathrm{~nm}^{3}$, such result implies that at room temperature the FiM shell is formed by several superparamagnetic clusters. 
Figure $3 \mathrm{a}$ reports the temperature dependence of the saturation magnetization, $M_{S}(T)$, normalized to the saturation magnetization extrapolated at zero temperature $\left(M_{0}\right)$. Both samples show a decrease of $M_{S}(T) / M_{0}$ when the temperature is raised, being this decay more pronounced for the $\mathrm{ZnO} / \mathrm{CoFe}_{2} \mathrm{O}_{4}$ system, particularly in the low temperature range $(T<50 \mathrm{~K})$ where a sharp reduction of $M_{S}(T)$ is observed. The decrease of the magnetization with temperature in an ordered magnetic system is related to the low energy collective excitations or spin waves. ${ }^{34}$ Such behavior can be analyzed through the modified Bloch expression given by

$$
M_{S}(T) / M_{0}=1-B T^{\alpha}+A_{0} e^{-T / T_{f}} \quad \text { (Equation 2) }
$$

where $\alpha$ and $B$ are parameters that depend on the characteristic of the magnetic system and the exponential term is a correction due the magnetically disordered layer that depends on the size of the particle through the fitting term $A_{0}$ and on a spin-glass freezing temperature given by $T_{f}$. While $\alpha=3 / 2$ has been observed for many bulk materials, in nanostructured magnetic materials deviations from $B_{b u l k}$ and $\alpha_{b u l k}$ are usually found. ${ }^{34,35}$ Hendriksen et al. in ref 35 took into account size effects in calculating the temperature dependence of the magnetic moment based on a thermal distribution of spin waves and obtained a power law with $\alpha=2$ and $B$ similar to the bulk value. The mentioned work remarks that the parameter $\alpha$ is size dependent but structure independent; on the other hand, $B$ is related to the effective coordination number of the magnetic cluster (mean number of nearest neighbors), where a larger $B$ corresponds to "open" clusters with a lower coordination number for the surface ions. For $\mathrm{CoFe}_{2} \mathrm{O}_{4}$, bulk $\alpha=2$ and $B \sim 1.6 \cdot 10^{-6} K^{-2}$ have been measured. ${ }^{36,37} B>B_{\text {bulk }}$ was found for small NPs and $B$ approaches the bulk value when the NPs' size increases. ${ }^{34,35}$ By fitting the data of Figure $3 \mathrm{a}$ with a fixed $\alpha=2$ 
we have found that the exponential term is negligible for $\mathrm{CoO} / \mathrm{CoFe}_{2} \mathrm{O}_{4} \mathrm{NPs}$ but that it should be taken into account for the low temperature increase observed for $\mathrm{ZnO} / \mathrm{CoFe}_{2} \mathrm{O}_{4}$, where $A_{0}=0.05$ and $T_{f}=10 \mathrm{~K}$ have been obtained. These results suggest that the $\mathrm{ZnO} / \mathrm{CoFe}_{2} \mathrm{O}_{4}$ system presents a larger magnetically disordered surface, while for the $\mathrm{CoO} / \mathrm{CoFe}_{2} \mathrm{O}_{4}$ NPs the AFM core promotes a higher degree of magnetic ordering of the FiM shell by the interface exchange interaction. Interestingly, while $B \sim 4.5 \cdot 10^{-6} K^{-2}$ is higher than $B_{\text {bulk }}$ for $\mathrm{ZnO} / \mathrm{CoFe}_{2} \mathrm{O}_{4}$ (as expected for nanostructured materials with a reduced mean number of nearest neighbors), $B \sim 1.1 \cdot 10^{-6} K^{-2}$ results even lower than $B_{\text {bulk }}$ for $\mathrm{CoO} / \mathrm{CoFe}_{2} \mathrm{O}_{4}$, highlighting the important effect of the exchange interaction at the AFM/FiM interface, which reduces the surface magnetic disorder by increasing the mean number of interacting nearest neighbors and enhances the magnetization thermal stability.

The temperature dependence of the coercive field for both systems is displayed in Figure $3 \mathrm{~b}$, where a monotonously decrease of $H_{C}$ with temperature is observed and an almost four times larger $H_{C}$ value for the $\mathrm{CoO} / \mathrm{CoFe}_{2} \mathrm{O}_{4}$ system is found compared to $\mathrm{ZnO} / \mathrm{CoFe} \mathrm{O}_{4}$. From the energy barrier, calculated for non-interacting and single-domain NPs in the presence of a magnetic field, the temperature dependence of $H_{C}$ results ${ }^{25}$

$$
\left.H_{C}(T)=H_{0}\left(1-\sqrt{T / T_{B}}\right) \quad \text { (Equation } 3\right)
$$

where the coercivity at the zero temperature limit, $H_{0}$, depends on the degree of alignment of the particles' easy axes. However, this well-known equation does not consider the size distribution and the intra- or inter-particle interactions that modify the energy barrier. The energy barrier distribution affects $H_{C}(T)$ because at a particular $T$ only particles with $T_{B}>T$ will contribute to the hysteresis; thus, a correction could be taken 
into account by replacing $T_{B}$ in Equation 3 with a temperature dependent mean blocking temperature $\left\langle T_{B}\right\rangle_{T}$, defined as follows: ${ }^{38}$

$$
\left.\left\langle T_{B}\right\rangle_{T}=\frac{\int_{T}^{\infty} T_{B} f\left(T_{B}\right) d T_{B}}{\int_{T}^{\infty} f\left(T_{B}\right) d T_{B}} \quad \text { (Equation } 4\right)
$$

The coercive field where only the blocked particles are considered is called $H_{C B}(T)$ and is expected to follow the Equation 3 modified by $\left\langle T_{B}\right\rangle_{T}$. On the other hand, when the temperature raises the fraction of superparamagnetic particles increases and, as a consequence, the average coercive field is reduced. According to refs 38,39 the mean coercive field for a mixture of superparamagnetic and blocked particles, $\left\langle H_{C}\right\rangle_{T}$, can be calculated from the linear contribution of the superparamagnetic and blocked components of magnetization. Within this approximation, $\left\langle H_{C}\right\rangle_{T}$ results

$$
\left\langle H_{C}\right\rangle_{T}=H_{C B}(T)\left(\frac{1}{1+\chi_{S}(T) H_{C B}(T) / M_{r}(T)}\right) \quad \text { (Equation 5) }
$$

where $\chi_{S}(T)$ is the superparamagnetic susceptibility given by $\chi_{S}(T)=\frac{25 M_{S}^{2}}{3 K T} \int_{0}^{T} T_{B} f\left(T_{B}\right) d T_{B}$. Considering the experimental values of $f\left(T_{B}\right)$, shown in the insets of Figure 2, the temperature dependence of $\left\langle H_{C}\right\rangle_{T}$ was calculated with $H_{0}$ as the only free parameter. The full lines in Figure $3 \mathrm{~b}$ show the fitting of the experimental data with Equation 5. Notice that, in spite of the complexity of the magnetization reversal process in bimagnetic core/shell NPs, we have obtained a good agreement because $f\left(T_{B}\right)$ includes overall terms that affect the energy barrier. ${ }^{40}$ In the particular case of the $\mathrm{ZnO} / \mathrm{CoFe}_{2} \mathrm{O}_{4} \mathrm{NPs}$ we have added to the superparamagnetic susceptibility contribution $\chi_{S}(T)$ a second $C / T$ term in order to account for the surface disorder contribution evidenced by the low temperature sharp decreasing of $M_{S}(T)$, where $\mathrm{C}=0.05$ emuKOe ${ }^{1} \mathrm{~cm}^{-3}$ was obtained. 


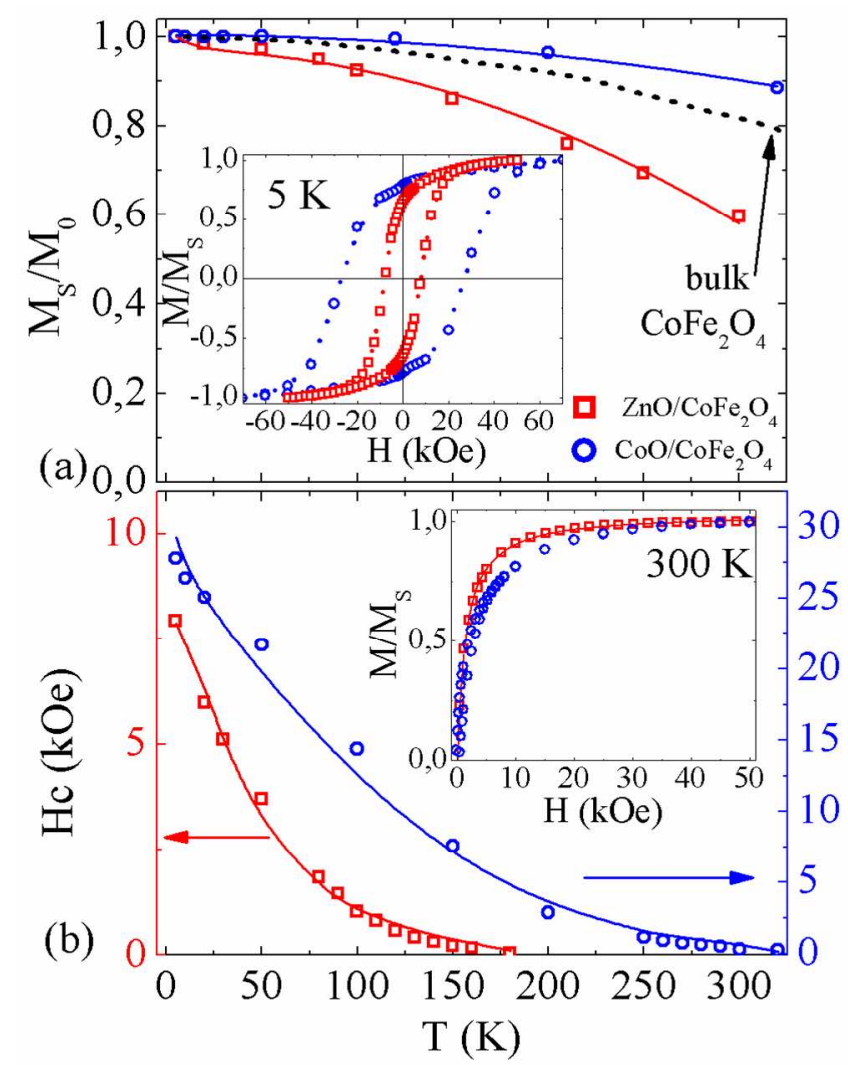

Figure 3 (a) Temperature dependence of the saturation magnetization ratio $M_{S} / M_{0}$ for $\mathrm{ZnO} / \mathrm{CoFe}_{2} \mathrm{O}_{4}$ and $\mathrm{CoO} / \mathrm{CoFe}_{2} \mathrm{O}_{4}$ nanoparticles (bulk $\mathrm{CoFe}_{2} \mathrm{O}_{4}$ experimental values from ref 41 are shown for comparison). Inset: Hysteresis loops at 5 K. (b) Temperature dependence of the coercive field. Inset: field dependence of magnetization at $300 \mathrm{~K}$. (full lines represent the corresponding fits).

\subsection{Intra- and inter-particle magnetic interactions}

\subsubsection{Remanent magnetization studies}

Magnetization remanence experiments were conducted to get a better comprehension of the role of interactions. ${ }^{42}$ The method consists in measuring an isothermal remanent magnetization curve (IRM) and a direct current demagnetization curve (DCD) from which information about interactions can be derived. By differentiating the remanence curves, a 
field dependent irreversible susceptibility $\left(\chi_{i r r}\right)$ can be calculated. $\chi_{i r r}(H)$ is related to the distribution of coercive fields and, in NPs, it is associated to the energy barrier distribution. $^{25,42-44}$ Figures $4 \mathrm{a}-\mathrm{b}$ show the IRM and DCD magnetization curves for $\mathrm{CoO} / \mathrm{CoFe}_{2} \mathrm{O}_{4}$ and $\mathrm{ZnO} / \mathrm{CoFe}_{2} \mathrm{O}_{4}$ NPs measured at $10 \mathrm{~K}$ and the insets show the corresponding $\chi_{\text {irr }}$. Wohlfarth predicted that non-interacting single-domain particles with uniaxial anisotropy follow the relation $m_{D C D}(H)=1-2 m_{I R M}(H),{ }^{45}$ where $m_{D C D}$ and $m_{I R M}$ stand for the remanent magnetization divided by the saturation remanent magnetization in DCD and IRM curves, respectively. Deviations from the equation above would indicate the presence of different interactions that affect the energy barrier: if $\delta m(H)=m_{D C D}(H)-\left[1-2 m_{I R M}(H)\right]<0$, then demagnetizing interactions are dominant, whereas $\delta m(H)>0$ implies the prevalence of magnetizing interactions. ${ }^{46}$

The $\delta m$ plots for $\mathrm{CoO} / \mathrm{CoFe}_{2} \mathrm{O}_{4}$ and $\mathrm{ZnO} / \mathrm{CoFe}_{2} \mathrm{O}_{4} \mathrm{NPs}$ measured at $10 \mathrm{~K}$ are shown in Figure $4 c$, both suggesting the presence of demagnetizing interactions. For $\mathrm{CoO} / \mathrm{CoFe}_{2} \mathrm{O}_{4}$ NPs $\delta m$ peak $(\Delta \mathrm{Hp})$ is centered around $27 \mathrm{kOe}$, while for $\mathrm{ZnO} / \mathrm{CoFe}_{2} \mathrm{O}_{4} \quad \mathrm{NPs} \Delta \mathrm{Hp}$ is shifted to lower fields (around $9 \mathrm{kOe}$ ) in agreement with the lower anisotropy of the last system. The interactions strength can be assessed by comparing the $\chi_{\text {irr }}(H)$ curves obtained from DCD and IRM; the difference between $H_{I R M}$ and $H_{D C D}$ magnetic fields associated to the maximum of $\chi_{\text {irr }}$ curves is related to an interaction field given by $H_{\text {int }}=\frac{H_{D C D}-H_{I R M}}{2}$. The strength of the interactions was evaluated by calculating the $H_{\text {int }}$, which resulted to be -0.1 kOe and $-0.9 \mathrm{kOe}$ for the $\mathrm{ZnO} / \mathrm{CoFe}_{2} \mathrm{O}_{4}$ and $\mathrm{CoO} / \mathrm{CoFe}_{2} \mathrm{O}_{4}$ samples, respectively. Given the demagnetizing nature and magnitude of the calculated interacting fields we ascribe them to the inter-particle dipolar interaction. The smaller $H_{\text {int }}$ value found for $\mathrm{ZnO} / \mathrm{CoFe} \mathrm{O}_{4}$ could 
be related to the smaller magnetic moment of the FiM shell due to the larger surface disorder as compared to the $\mathrm{CoO} / \mathrm{CoFe}_{2} \mathrm{O}_{4}$ system.
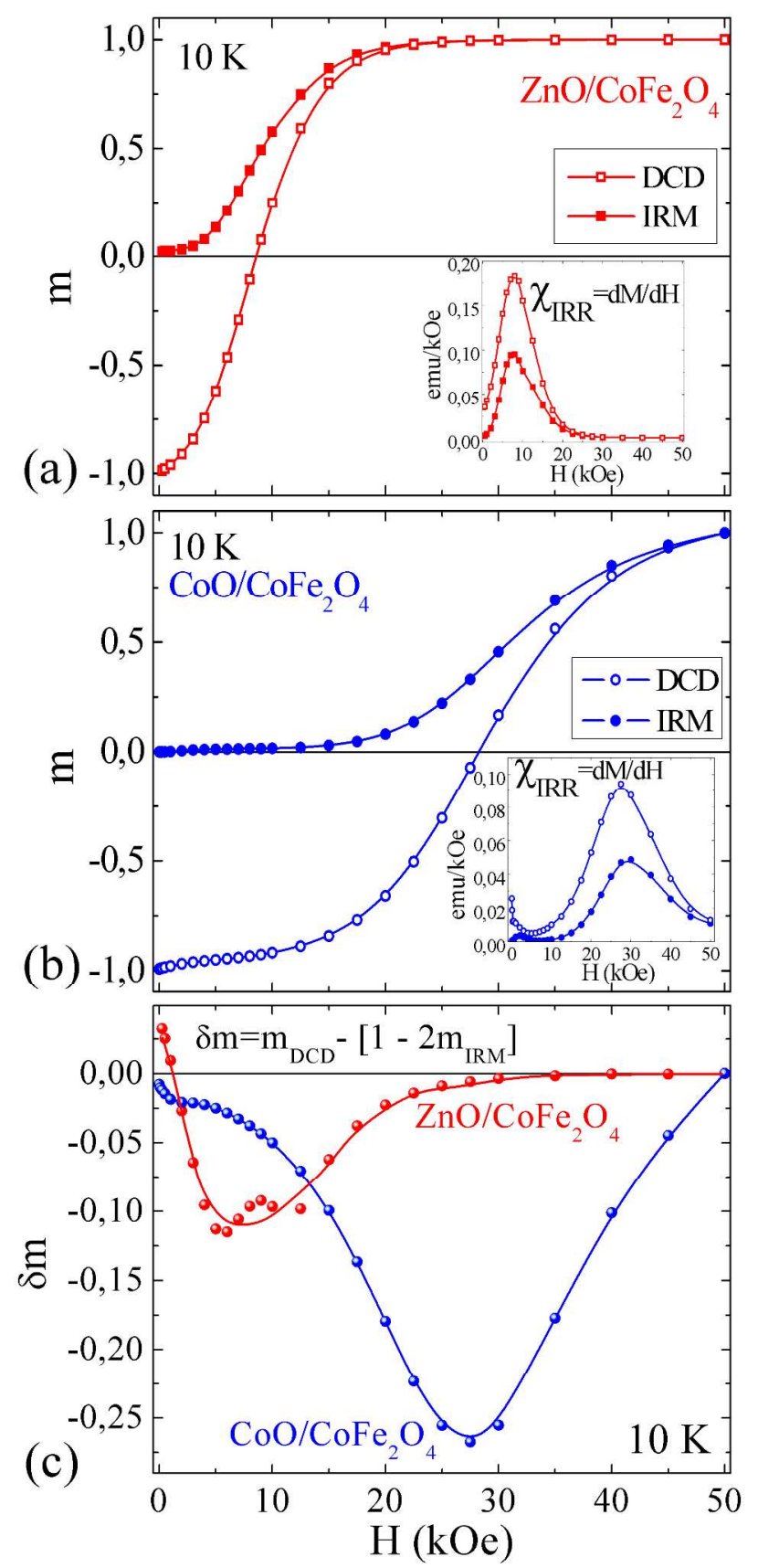

Figure 4 DCD (empty symbols) and IRM (full symbols) curves for (a) $\mathrm{ZnO} / \mathrm{CoFe} 2 \mathrm{O} 4$ nanoparticles and (b) $\mathrm{CoO} / \mathrm{CoFe} 2 \mathrm{O} 4$ nanoparticles measured at $10 \mathrm{~K}$. (c) $\delta m$ plots and 
(insets) irreversible susceptibilities calculated from the DCD and IRM curves (lines are a guide to the eye).

\subsubsection{Magnetic relaxation and activation volumes}

A further insight in the reversal of magnetization can be attained by performing magnetic relaxation measurements. These experiments, mainly employed in the characterization of recording media to determine the stability of the stored information, have also been employed to study the time-dependent properties of permanent magnets. ${ }^{47,48}$ Moreover, relaxation measurements provide information about the magnetization reversal and the origin of hysteretic behavior. ${ }^{49-51}$ In NPs' systems, the time relaxation of the magnetization is originated by the thermally activated reversal of the magnetization against the energy barriers of the system. It is frequently described by the logarithmic decay given by Equation 6, where $S$ denotes the magnetic viscosity coefficient, $t$ is the time, $t_{0}$ is a reference time and $M\left(t_{0}\right)$ is the magnetization value at $t_{0}$,

$$
M(t)=M\left(t_{0}\right)+\operatorname{Sln}\left(t / t_{0}\right) \quad(\text { Equation } 6)
$$

The magnetic viscosity depends on the field at which the magnetization is recorded and tends to be maximum close to the coercive field, reflecting the link between $S$ and the energy barrier distribution represented by $\chi_{i r r}(H) .{ }^{50}$ By measuring $M(t)$ at different applied fields (as shown in Figure S3) and fitting the results according to Equation 6 then $S(H)$ can be obtained as it is shown in Figure 5.

From the maximum values of $S(H)$ and $\chi_{i r r}(H)$ a fluctuation field defined as $H_{f}=$ $S^{M A X} / \chi_{i r r}^{M A X}$ can be calculated. ${ }^{44} H_{f}$ is related to the activation volume $\left(V_{A C T}\right)$ where the magnetization reversal initiates through $V_{A C T}=k_{B} T /\left(M_{S} H_{f}\right) .{ }^{50,52} V_{A C T}$ can be defined as the smallest volume of the material that reverses coherently in an event ${ }^{53}$. From the $H_{f}$ 
value obtained at $10 \mathrm{~K}$ we calculated the activation volume for both systems, that resulted to be $69(5) \mathrm{nm}^{3}$ and $46(6) \mathrm{nm}^{3}$ for $\mathrm{ZnO} / \mathrm{CoFe}_{2} \mathrm{O}_{4}$ and $\mathrm{CoO} / \mathrm{CoFe}_{2} \mathrm{O}_{4}$, respectively, as reported in Table 1. In the case of non-interacting single-domain NPs, the activation volume is equal to the particle size, however local effects tend to reduce $V_{A C T}{ }^{52}$ Considering the total $\mathrm{CoFe}_{2} \mathrm{O}_{4}$ shell volume $\mathrm{V} \sim 235 \mathrm{~nm}^{3}$, which is similar for both systems, we found that the activation volume is three times smaller than $\mathrm{V}$ when the core is $\mathrm{ZnO}$ and five times smaller for the $\mathrm{CoO}$ case. The nucleation of magnetization reversal that defines the activation or switching field can be originated by local variations of anisotropy and structural disorder. Nucleation and interactions are competing processes ${ }^{54}$ and, in this sense, the AFM-FiM coupling in $\mathrm{CoO} / \mathrm{CoFe}_{2} \mathrm{O}_{4}$ is promoting a greater degree of incoherent rotation. $^{48}$

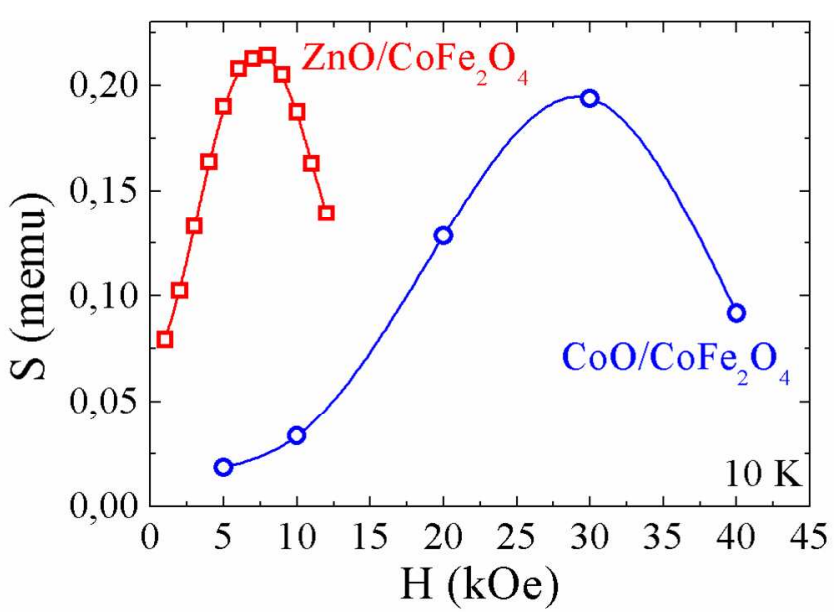

Figure 5 Magnetic viscosity coefficient (S) as a function of the reverse field for $\mathrm{ZnO} / \mathrm{CoFe}_{2} \mathrm{O}_{4}$ and $\mathrm{CoO} / \mathrm{CoFe}_{2} \mathrm{O}_{4}$ nanoparticles (lines are a guide to the eye).

In the Stoner-Wohlfarth model for non-interacting NPs with uniaxial anisotropy the activation volume can be calculated by $V_{A C T}=V{\sqrt{\frac{25 k_{B} T}{K V}}}^{50}$ where $V$ denotes the physical volume and $K$ the effective magnetic anisotropy. Such relationship can be rewritten in 
terms of the mean blocking temperature as $V_{A C T}=V \sqrt{\frac{T}{\left\langle T_{B}\right\rangle}}$, then, the expected $V_{A C T}$ can be simply derived from measured parameters. Such calculations lead to a $V_{A C T}$ of $45(2) \mathrm{nm}^{3}$ and $72(3) \mathrm{nm}^{3}$ for $\mathrm{CoO} / \mathrm{CoFe}_{2} \mathrm{O}_{4}$ and $\mathrm{ZnO} / \mathrm{CoFe}_{2} \mathrm{O}_{4}$, respectively. It can be noted that the calculated $V_{A C T}$ through the equation above and the measured $V_{A C T}$ reported in Table 1 are in good agreement and come from independent measurements. Consequently, it seems clear that the smaller $V_{A C T}$ found for $\mathrm{CoO} / \mathrm{CoFe}_{2} \mathrm{O}_{4}$ is originated by the same mechanism that increases the thermal stability, i.e. the intra-particle interactions.

The strength of the intra-particle interaction can be estimated from the energy barrier. In the simplest model the energy barrier of the nanoparticle is originated by the contribution of different terms that account for the interactions of the system,

$$
\Delta E=\Delta E_{0}+\Delta E_{\text {intra }}+\Delta E_{\text {inter }} \quad(\text { Equation } 7)
$$

where $\Delta E_{0}$ arises from the magnetocrystalline, surface and shape anisotropy and $\Delta E_{\text {intra }}$, $\Delta E_{\text {inter }}$ account for the intra-particle and inter-particle interactions respectively. In spite of the complexity of the magnetic systems (multiple energy minima, multi-domain particles) arising from the core/shell structure, Equation 7 simplifies the picture by considering the contributions of intra- and inter-particle interactions to an energy barrier in an Arrhenius thermal activated process. Assuming this approximation, from the Néel equation and the calculated mean blocking temperature we can estimate $\Delta E=25 k_{B}\left\langle T_{B}\right\rangle$ for $\mathrm{ZnO} / \mathrm{CoFe}_{2} \mathrm{O}_{4}$ and $\mathrm{CoO} / \mathrm{CoFe}_{2} \mathrm{O}_{4}$ NPs. If we assume that $\Delta E_{0}$ and $\Delta E_{\text {inter }}$ are similar for both systems, the differences between the energy barriers could be then explained by the intra-particle interactions, only present in $\mathrm{CoO} / \mathrm{CoFe}_{2} \mathrm{O}_{4}$ due the interface exchange interaction. To compare the strength of such interactions we can associate an effective magnetic field to the 
$\Delta E_{\text {intra }}$ through $\Delta E_{\text {intra }} \sim H_{\text {intra }} M_{S} V_{A C T}$. In this way, using the experimental $V_{A C T}$ values and a $M_{S} \sim 80 \mathrm{emu} / \mathrm{g}$, the intra-particle interaction field results to be $H_{\text {intra }} \sim 24 \mathrm{kOe}$. It is worth noting that the calculated interaction field is much larger than the interaction fields estimated from the remanence study $\left(-0.1 \mathrm{kOe}\right.$ and $-0.9 \mathrm{kOe}$ for $\mathrm{ZnO} / \mathrm{CoFe}_{2} \mathrm{O}_{4}$ and $\mathrm{CoO} / \mathrm{CoFe}_{2} \mathrm{O}_{4}$ samples, respectively), supporting its exchange-coupling origin. Therefore, the remanence measurements allow to quantify the strength of dipolar inter-particle interactions of these systems but fail to account for the intra-particle interaction probably because of the strong coupling between the AFM and FiM phases and, according to ref 55, $\delta m(H)$ curve does not account for cooperative effects. These features are in agreement with a magnetization reversal process where the interface exchange interaction, $\mathrm{J}_{\mathrm{INT}}$, is much larger than the AFM anisotropy of the core $\left(J_{I N T} \gg K_{A F M} V_{A F M}\right)$ and, as a consequence, it is energetically more favorable for the spins in both FiM and AFM to rotate together. ${ }^{56}$ This picture is consistent with the enhancement of the coercive field and the absence of exchange bias fields in the AFM-core/FiM-shell NPs. ${ }^{23}$

\section{CONCLUSIONS}

New bimagnetic nanoparticles systems have been proposed in the last years and their increasing complexity requires comprehensive magnetic studies in order to understand their properties. In this work, we have studied two core/shell magnetic systems, one formed by a diamagnetic core surrounded by ferrimagnetic $\mathrm{CoFe}_{2} \mathrm{O}_{4}$ and the other formed by an antiferromagnetic core surrounded by ferrimagnetic $\mathrm{CoFe}_{2} \mathrm{O}_{4}$. Since both systems present comparable size and morphology, from our studies some general issues about core/shell systems can be discussed. First, it is worth noting that core/shell NPs with a core that 
occupies $\sim 12 \%$ of the total NP volume present magnetic properties that strongly depend on the magnetic nature of the core material and that are very different compared to singlephase particles of similar volume.

For the non-magnetic core the results can be interpreted by dominant surface effects induced into the ferrimagnetic phase by the shell morphology. The large magnetic surface disorder of the FiM shell is reflected in the $\mathrm{M}_{\mathrm{S}}$ reduction with temperature and in the relatively low $\mathrm{H}_{\mathrm{C}}$ compared to single-phase $\mathrm{CoFe}_{2} \mathrm{O}_{4} \mathrm{NPs}$, whose low-temperature $\mathrm{H}_{\mathrm{C}}$ was found to be between 10 and $18 \mathrm{kOe} .{ }^{57-60}$ In addition, viscosity measurements suggest that the activation or switching volume is nearly a third of the total shell volume, even if the total volume is lower than the critical single-domain volume. Such results evidence the importance of local effects, e.g. local structural and compositional inhomogeneities, on the reversal process. ${ }^{54,61}$ On the contrary, the exchange interaction at the interface reduces the magnetic surface disorder in $\mathrm{CoO} / \mathrm{CoFe}_{2} \mathrm{O}_{4}$ as it is reflected by the weak temperature dependence of the $M_{S}(T)$, in agreement with previous studies of the effects of interactions on the NPs' properties. ${ }^{62}$ The magnetic behavior of $\mathrm{CoO} / \mathrm{CoFe}{ }_{2} \mathrm{O}_{4} \mathrm{NPs}$ is governed by the intra-particle interactions that lead to an enhancement of the thermal stability and a magnetic hardening of the system. The strength of the intra-particle interactions estimated from the energy barrier is much larger than the interaction fields estimated from the remanence study supporting its exchange-coupling origin. Finally, by combining remanence and relaxation studies we have presented a direct measurement of how the exchange anisotropy in bimagnetic NPs rules the magnetization reversal by promoting a smaller switching volume, nearly a fifth of the total $\mathrm{CoFe}_{2} \mathrm{O}_{4}$ shell volume. Therefore the interface exchange coupling, apart from increasing the energy barrier, may be responsible for a greater degree of incoherent rotation. 
In conclusion, to understand of how the static and dynamic energy landscape is related to the real structure of the material is important for the development of new artificial structures. The present study intends to clarify the determining role played by the morphology, the surface disorder, as well as the inter- and intra-particle interactions in the reversal magnetization process, and could orient future materials' development with tuned magnetic properties.

\author{
AUTHOR INFORMATION \\ Corresponding author \\ * E-mail: winkler@cab.cnea.gov.ar. Tel: +54-294-4445180
}

\title{
ACKNOWLEDGEMENTS
}

The authors thank ANPCyT Argentina through Grant PICT-2012-0492, CONICET Argentina through Grant PIP 112-20110100519, UNCuyo Argentina through Grants 06C404 and C011, the Bilateral Project Argentina-CNR common projects 2013-2014 and the Joint Laboratory LIANAM.

\section{ASSOCIATED CONTENT \\ Supporting Information}

Temperature and time dependence of magnetization at different applied fields, for $\mathrm{ZnO} / \mathrm{CoFe}_{2} \mathrm{O}_{4}$ and $\mathrm{CoO} / \mathrm{CoFe}_{2} \mathrm{O}_{4} \mathrm{NPs}$ and distributions of blocking temperatures at different applied fields for $\mathrm{CoO} / \mathrm{CoFe}_{2} \mathrm{O}_{4}$ NPs. This information is available free of charge via the Internet at http://pubs.acs.org. 


\section{REFERENCES}

(1) Sort, J.; Nogués, J.; Suriñach, S.; Muñoz, J. S.; Baró, M. D.; Chappel, E.; Dupont, F.; Chouteau, G. Coercivity and Squareness Enhancement in Ball-Milled Hard Magnetic-antiferromagnetic Composites. Appl. Phys. Lett. 2001, 79, 1142.

(2) Reiss, G.; Hütten, A. Magnetic Nanoparticles: Applications beyond Data Storage. Nat. Mater. 2005, 4, 725-726.

(3) Black, C. T.; Murray, C. B.; Sandstrom, R. L.; Sun, S. Spin-Dependent Tunneling in Self-Assembled Cobalt-Nanocrystal Superlattices. Science 2000, 290, 1131-1134.

(4) Dai, Q.; Berman, D.; Virwani, K.; Frommer, J.; Jubert, P.-O.; Lam, M.; Topuria, T.; Imaino, W.; Nelson, A. Self-Assembled Ferrimagnet--Polymer Composites for Magnetic Recording Media. Nano Lett. 2010, 10, 3216-3221.

Liu, F.; Zhu, J.; Yang, W.; Dong, Y.; Hou, Y.; Zhang, C.; Yin, H.; Sun, S. Building Nanocomposite Magnets by Coating a Hard Magnetic Core with a Soft Magnetic Shell. Angew. Chem. Int. Ed. Engl. 2014, 53, 2176-2180.

(6) Zeng, H.; Li, J.; Liu, J. P.; Wang, Z. L.; Sun, S. Exchange-Coupled Nanocomposite Magnets by Nanoparticle Self-Assembly. Nature 2002, 420, 395-398.

(7) Balamurugan, B.; Sellmyer, D. J.; Hadjipanayis, G. C.; Skomski, R. Prospects for Nanoparticle-Based Permanent Magnets. Scr. Mater. 2012, 67, 542-547.

(8) Sort, J.; Suriñach, S.; Muñoz, J.; Baró, M.; Nogués, J.; Chouteau, G.; Skumryev, V.; Hadjipanayis, G. Improving the Energy Product of Hard Magnetic Materials. Phys. Rev. B 2002, 65, 174420 .

(9) Liu, H.; Wu, J.; Min, J. H.; Zhang, X.; Kim, Y. K. Tunable Synthesis and Multifunctionalities of $\mathrm{Fe}_{3} \mathrm{O}_{4}-\mathrm{ZnO}$ Hybrid Core-Shell Nanocrystals. Mater. Res. Bull. 2013, 48, 551-558.

(10) Lu, A.-H.; Salabas, E. L.; Schüth, F. Magnetic Nanoparticles: Synthesis, Protection, Functionalization, and Application. Angew. Chem. Int. Ed. Engl. 2007, 46, 12221244.

(11) Gupta, A. K.; Gupta, M. Synthesis and Surface Engineering of Iron Oxide Nanoparticles for Biomedical Applications. Biomaterials 2005, 26, 3995-4021.

(12) Cho, N.-H.; Cheong, T.-C.; Min, J. H.; Wu, J. H.; Lee, S. J.; Kim, D.; Yang, J.-S.; Kim, S.; Kim, Y. K.; Seong, S.-Y. A Multifunctional Core-Shell Nanoparticle for Dendritic Cell-Based Cancer Immunotherapy. Nat. Nanotechnol. 2011, 6, 675-682. 
(13) Nandwana, V.; Chaubey, G. S.; Yano, K.; Rong, C.; Liu, J. P. Bimagnetic Nanoparticles with Enhanced Exchange Coupling and Energy Products. J. Appl. Phys. 2009, 105, 014303.

(14) López-Ortega, A.; Tobia, D.; Winkler, E.; Golosovsky, I. V; Salazar-Alvarez, G.; Estradé, S.; Estrader, M.; Sort, J.; González, M. A.; Suriñach, S.; et al. SizeDependent Passivation Shell and Magnetic Properties in Antiferromagnetic/ferrimagnetic Core/shell MnO Nanoparticles. J. Am. Chem. Soc. 2010, 132, 9398-9407.

(15) H. Zeng Z.L. Wang, J.P. Liu and S. Sun, J. L. Bimagnetic Core/Shell FePt/Fe $\mathrm{O}_{4}$ Nanoparticles. Nano Lett. 2004, 4, 187-190.

(16) Lavorato, G. C.; Lima Jr, E.; Tobia, D.; Fiorani, D.; Troiani, H. E.; Zysler, R. D.; Winkler, E. L. Size Effects in Bimagnetic $\mathrm{CoO} / \mathrm{CoFe}_{2} \mathrm{O}_{4}$ Core/shell Nanoparticles. Nanotechnology 2014, 25, 355704.

(17) Binns, C.; Qureshi, M. T.; Peddis, D.; Baker, S. H.; Howes, P. B.; Boatwright, A.; Cavill, S. A.; Dhesi, S. S.; Lari, L.; Kröger, R.; et al. Exchange Bias in Fe@Cr CoreShell Nanoparticles. Nano Lett. 2013, 13, 3334-3339.

(18) Lima, E.; Winkler, E. L.; Tobia, D.; Troiani, H. E.; Zysler, R. D.; Agostinelli, E.; Fiorani, D. Bimagnetic CoO Core $/ \mathrm{CoFe}_{2} \mathrm{O}_{4}$ Shell Nanoparticles: Synthesis and Magnetic Properties. Chem. Mater. 2012, 24, 512-516.

(19) Sun, X.; Huls, N. F.; Sigdel, A.; Sun, S. Tuning Exchange Bias in Core/shell $\mathrm{FeO} / \mathrm{Fe}_{3} \mathrm{O}_{4}$ Nanoparticles. Nano Lett. 2012, 12, 246-251.

(20) Baaziz, W.; Pichon, B. P.; Lefevre, C.; Ulhaq-Bouillet, C.; Greneche, J.-M.; Toumi, M.; Mhiri, T.; Bégin-Colin, S. High Exchange Bias in $\mathrm{Fe}_{3-\delta} \mathrm{O}_{4} @ \mathrm{CoO}$ Core Shell Nanoparticles Synthesized by a One-Pot Seed-Mediated Growth Method. J. Phys. Chem. C 2013, 117, 11436-11443.

(21) Sun, S.; Zeng, H. Size-Controlled Synthesis of Magnetite Nanoparticles. J. Am. Chem. Soc. 2002, 124, 8204-8205.

(22) Kwon, S. G.; Hyeon, T. Formation Mechanisms of Uniform Nanocrystals via HotInjection and Heat-up Methods. Small 2011, 7, 2685-2702.

(23) Winkler, E. L.; Lima, E.; Tobia, D.; Saleta, M. E.; Troiani, H. E.; Agostinelli, E.; Fiorani, D.; Zysler, R. D. Origin of Magnetic Anisotropy in $\mathrm{ZnO} / \mathrm{CoFe}_{2} \mathrm{O}_{4}$ and $\mathrm{CoO} / \mathrm{CoFe}_{2} \mathrm{O}_{4}$ Core/shell Nanoparticle Systems. Appl. Phys. Lett. 2012, 101, 252405 . 
(24) Lavorato, G. C.; Lima, E.; Troiani, H. E.; Zysler, R. D.; Winkler, E. L. ExchangeCoupling in Thermal Annealed Bimagnetic Core/shell Nanoparticles. J. Alloys Compd. 2015, 633, 333-337.

(25) Dormann, J. L.; Fiorani, D.; Tronc, E. Magnetic Relaxation in Fine-Particle Systems. Advanced in Chemical Physics Vol XCVIII; Wiley: New York, 1997.

(26) Peddis, D.; Cannas, C.; Musinu, A.; Ardu, A.; Orrù, F.; Fiorani, D.; Laureti, S.; Rinaldi, D.; Muscas, G.; Concas, G.; et al. Beyond the Effect of Particle Size: Influence of $\mathrm{CoFe}_{2} \mathrm{O}_{4}$ Nanoparticle Arrangements on Magnetic Properties. Chem. Mater. 2013, 25, 2005-2013.

(27) Chantrell, R. W.; El-Hilo, M.; O’Grady, K. Spin-Glass Behavior in a Fine Particle System. IEEE Trans. Magn. 1991, 27, 3570-3578.

(28) Dormann, J. L.; Fiorani, D.; El Yamani, M. Field Dependence of the Blocking Temperature in the Superparamagnetic Model: H2/3 Coincidence. Phys. Lett. A 1987, 120, 95-99.

(29) Nunes, W.; Socolovsky, L.; Denardin, J.; Cebollada, F.; Brandl, A.; Knobel, M. Role of Magnetic Interparticle Coupling on the Field Dependence of the Superparamagnetic Relaxation Time. Phys. Rev. B 2005, 72, 212413.

(30) M. El-Hilo, K. O. and R. W. C. Susceptibility Phenomena in a Fine Particle System. J. Magn. Magn. Mater. 1992, 114, 307-313.

(31) Peddis, D.; Rinaldi, D.; Ennas, G.; Scano, a.; Agostinelli, E.; Fiorani, D. Superparamagnetic Blocking and Superspin-Glass Freezing in Ultra Small $\Delta$ (Fe0.67Mn0.33)OOH Particles. Phys. Chem. Chem. Phys. 2012, 14, 3162.

(32) Chantrell, R.; Popplewell, J.; Charles, S. Measurements of Particle Size Distribution Parameters in Ferrofluids. IEEE Trans. Magn. 1978, 14, 975-977.

(33) Cullity, B. D.; Graham, C. D. Introducion to Magnetic Materials; 2nd ed.; John Wiley \& Sons: New Jersey, 2009.

(34) Kodama, R. H. Magnetic Nanoparticles. J. Magn. Magn. Mater. 1999, 200, 359372 .

(35) Hendriksen, P. V; Linderoth, S.; Lindgard, P. Magnetic Properties of Heisenberg Clusters. J. Phys. Condens. Matter 1993, 5, 5675-5684.

(36) Vázquez-Vázquez, C.; López-Quintela, M. a.; Buján-Núñez, M. C.; Rivas, J. Finite Size and Surface Effects on the Magnetic Properties of Cobalt Ferrite Nanoparticles. J. Nanoparticle Res. 2010, 13, 1663-1676. 
(37) McDannald, A.; Staruch, M.; Jain, M. Surface Contributions to the Alternating Current and Direct Current Magnetic Properties of Oleic Acid Coated $\mathrm{CoFe}_{2} \mathrm{O}_{4}$ Nanoparticles. J. Appl. Phys. 2012, 112, 123916.

(38) Nunes, W.; Folly, W.; Sinnecker, J.; Novak, M. Temperature Dependence of the Coercive Field in Single-Domain Particle Systems. Phys. Rev. B 2004, 70, 014419.

(39) Kneller, E. F.; Luborsky, F. E. Particle Size Dependence of Coercivity and Remanence of Single-Domain Particles. J. Appl. Phys. 1963, 34, 656-658.

(40) Curiale, J.; Sánchez, R.; Troiani, H.; Ramos, C.; Pastoriza, H.; Leyva, a.; Levy, P. Magnetism of Manganite Nanotubes Constituted by Assembled Nanoparticles. Phys. Rev. B 2007, 75, 224410.

(41) Shenker, H. Magnetic Anisotropy of Cobalt Ferrite $\left(\mathrm{Co}_{1.01} \mathrm{Fe}_{2.00} \mathrm{O}_{3.62}\right)$ and Nickel Cobalt Ferrite $\left(\mathrm{Ni}_{0.72} \mathrm{Fe}_{0.20} \mathrm{Co}_{0.08} \mathrm{Fe}_{2} \mathrm{O}_{4}\right)$. Phys. Rev. 1957, 107, 1246-1249.

(42) Binns, C. Nanomagnetism: Fundamentals and Applications; Frontiers of Nanoscience; Elsevier Science, 2014.

(43) O'Grady, K.; El-Hilo, M.; Chantrell, R. W. The Characterisation of Interaction Effects in Fine Particle Systems. IEEE Trans. Magn. 1993, 29, 2608-2613.

(44) Laureti, S.; Varvaro, G.; Testa, A. M.; Fiorani, D.; Agostinelli, E.; Piccaluga, G.; Musinu, A.; Ardu, A.; Peddis, D. Magnetic Interactions in Silica Coated Nanoporous Assemblies of $\mathrm{CoFe}_{2} \mathrm{O}_{4}$ Nanoparticles with Cubic Magnetic Anisotropy. Nanotechnology 2010, 21, 315701.

(45) Wohlfarth, E. P. Relations between Different Modes of Acquisition of the Remanent Magnetization of Ferromagnetic Particles. J. Appl. Phys. 1958, 29, 595.

(46) Kelly, P. E.; O'Grady, K.; Mayo, P. I.; Chantrell, R. W. Switching Mechanisms in Cobalt-Phosphorus Thin Films. IEEE Trans. Magn. 1989, 25, 3881-3883.

(47) Street, R.; Woolley, J. C. A Study of Magnetic Viscosity. Proc. Phys. Soc. Sect. A 1949, 62, 562-572.

(48) Chantrell, R. Magnetic Viscosity of Recording Media. J. Magn. Magn. Mater. 1991, 95, 365-378.

(49) Antonel, P. S.; Negri, R. M.; Leyva, A. G.; Jorge, G. A. Anisotropy and Relaxation Processes of Uniaxially Oriented $\mathrm{CoFe}_{2} \mathrm{O}_{4}$ Nanoparticles Dispersed in PDMS. Phys. B Condens. Matter 2012, 407, 3165-3167.

(50) Bertotti, G. Hysteresis in Magnetism: For Physicists, Materials Scientists, and Engineers; Academic Press series in electromagnetism; Academic Press, 1998. 
(51) Butera, A.; Weston, J. L.; Barnard, J. A. Activation Volumes and Interparticle Interaction Effects in Nanostructured Fe Networks. J. Appl. Phys. 1997, 81, 7432.

(52) Patel, V.; EL-Hilo, M.; O’Grady, K.; Chantrell, R. W. Nucleation Fields in an Exchange Spring Hard Magnet. J. Phys. D. Appl. Phys. 1993, 26, 1453-1458.

(53) O'Grady, K.; Laidler, H. The Limits to Magnetic Recording - Media Considerations. J. Magn. Magn. Mater. 1999, 200, 616-633.

(54) Skomski, R. Nanomagnetics. J. Phys. Condens. Matter 2003, 15, R841-R896.

(55) Skomski, R.; Sellmyer, D. J. Cooperative Magnetism and the Preisach Model. J. Appl. Phys. 2001, 89, 7263-7265.

(56) Nogués, J.; Schuller, I. K. Exchange Bias. J. Magn. Magn. Mater. 1999, 192, 203232.

(57) Vestal, C. R.; Song, Q.; Zhang, Z. J. Effects of Interparticle Interactions upon the Magnetic Properties of $\mathrm{CoFe}_{2} \mathrm{O}_{4}$ and $\mathrm{MnFe}_{2} \mathrm{O}_{4}$ Nanocrystals. J. Phys. Chem. B 2004, 108, 18222-18227.

(58) Pianciola, B. N.; Lima, E.; Troiani, H. E.; Nagamine, L. C. C. M.; Cohen, R.; Zysler, R. D. Journal of Magnetism and Magnetic Materials Size and Surface Effects in the Magnetic Order of $\mathrm{CoFe}_{2} \mathrm{O}_{4}$ Nanoparticles. J. Magn. Magn. Mater. 2015, 377, 44 51 .

(59) Peddis, D.; Orrù, F.; Ardu, A.; Cannas, C.; Musinu, A.; Piccaluga, G. Interparticle Interactions and Magnetic Anisotropy in Cobalt Ferrite Nanoparticles: Influence of Molecular Coating. Chem. Mater. 2012, 24, 1062-1071.

(60) Cannas, C.; Musinu, A.; Piccaluga, G.; Fiorani, D.; Peddis, D.; Rasmussen, H. K.; Mørup, S. Magnetic Properties of Cobalt Ferrite-Silica Nanocomposites Prepared by a Sol-Gel Autocombustion Technique. J. Chem. Phys. 2006, 125, 164714.

(61) Zeng, H.; Skomski, R.; Menon, L.; Liu, Y.; Bandyopadhyay, S.; Sellmyer, D. Structure and Magnetic Properties of Ferromagnetic Nanowires in Self-Assembled Arrays. Phys. Rev. B 2002, 65, 1-8.

(62) Winkler, E.; Zysler, R.; Fiorani, D. Surface and Magnetic Interaction Effects in $\mathrm{Mn}_{3} \mathrm{O}_{4}$ Nanoparticles. Phys. Rev. B 2004, 70, 174406. 


\section{TABLE OF CONTENTS GRAPHICS}

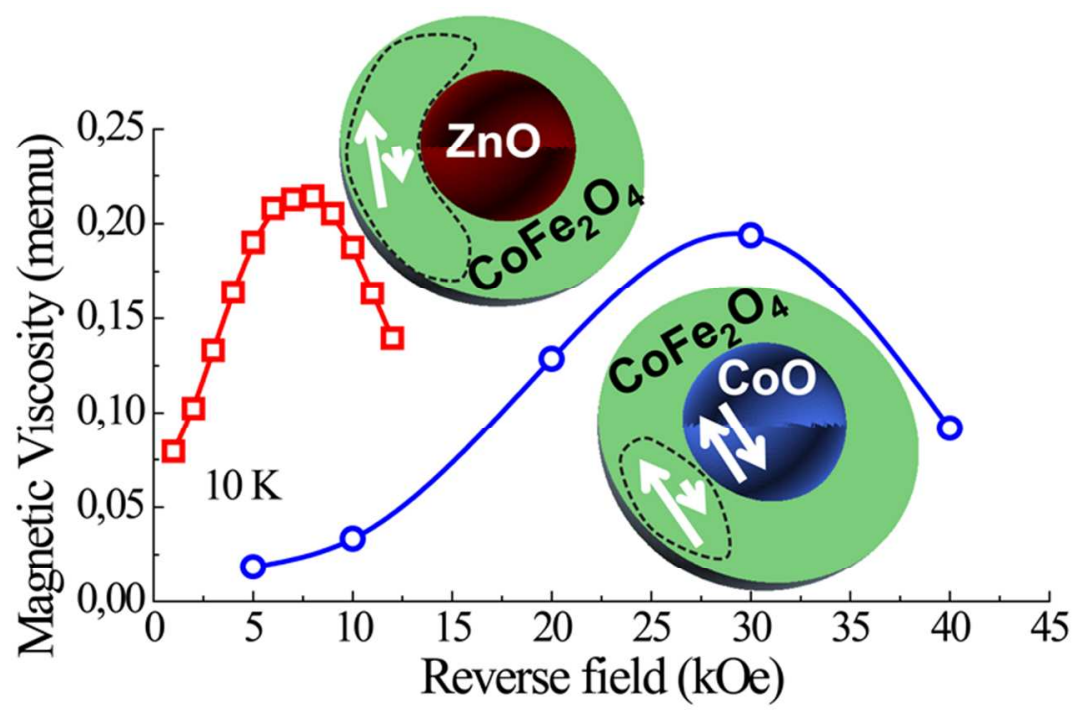

